\title{
Teachers' Attitude Towards the Inclusion of Students With Disabilities in the Regular Classroom: The Case of Selected Primary Schools in South Gondar Administrative Towns-Ethiopia
}

\author{
Getachew Walelign Asres
}

Correspondence: Getachew Walelign Asres, Debre Tabor University-Ethiopia.

Received: January 19, 2019

doi:10.11114/jets.v7i12.4636
Accepted: November 18, $2019 \quad$ Online Published: November 27, 2019

URL: https://doi.org/10.11114/jets.v7i12.4636

\begin{abstract}
The participants of this study were general primary school teachers. The data gathering instrument were questionnaire. Quantitative data analysis method were employed to compute the data obtained through questionnaire. The result showed that the general actual mean score of teachers' attitude scale is fairly greater than the cut point mean score. Due to this reason, teachers had fairly positive attitude to the inclusion of students with disabilities in to the mainstream classroom. It is recommended that the ministry of education should include special needs education courses to the college and university training program so that all the would be graduate teachers would get an opportunity to scale up their knowledge and skills about special needs education.
\end{abstract}

Keywords: attitude, teachers, students with disabilities, attitude of teachers, inclusion

\section{Introduction}

Educating all children together regardless of their physical and mental abilities is not a new concept (Leyser, \& Tappendorf, 2001). Numerous international declarations and guidelines have been signed in relation to the educational opportunities of students with disabilities in to the regular classroom- Including the Universal Declaration of Human Rights (1948), United Nation's Convention on The Rights of the Child (1989), The Salamanca statement (1994), and the UNESCO's document from 2005 'guidelines for inclusion ensuring access to education for all. Including a student with disability into a regular school program is an important aspect of the concept of participation and is seen as a basic human right (Florian, 2008). One of the most important aspects of the classroom interaction concerns the ways in which teachers make sense of and respond to, the learning behaviors of their students. It is the teacher's attitudes and expectations that will either improve or worsen the students' academic performances (Gaad, 2007).

Similarly, teachers' attitudes are an important factor in determining the success or otherwise of such policies (Ainscow, 1993; Ward, Center \& Bochner, 1994). In particular, it seems unlikely that the implementation of inclusive educational practices will be successful without the co-operation and commitment of those directly involved. While most attention was initially given to the ways in which negative teacher attitudes can present barriers to inclusion, the mechanisms through which positive teacher attitudes can facilitate inclusion are increasingly being considered. Van Reusen, Shoho and Barker (2001) hypothesize that the attitudes and beliefs that teachers, administrators and other school personnel hold towards inclusion and the learning ability of students with disabilities may influence school learning environments and the availability of equitable educational opportunities for all students. It is argued that teachers' beliefs and attitudes are critical in ensuring the success of inclusion practices since teachers' acceptance of the policy of inclusion is likely to affect their commitment to implementing it (Norwich, 1994).

However, the findings from previous studies have been mixed. That is, as $\mathrm{t}$ research identified teachers' attitudes to inclusion are classified their attitudes into three groups; negative, positive, and neutrals. Accordingly, some researchers have found that general education teachers were not in favor of inclusion (Gaad, 2007)). Due to this fact, teachers had negative attitudes towards including students with disabilities into the regular classroom (Designer (2000). In addition, other research findings has been evidenced that, when first confronted with the prospect of integrating students with disabilities in their own classes, teachers tend to be somewhat negative and uncertain about their own ability to cope, and they often point to lack of personal experience and relevant training ( Vaughn, Schumm, Jallard, Slusher, \& Saumell, 
1996). Designer (2000) points out that many teachers would not have had direct personal contact with students who have disabilities, and therefore their own attitudes tend to be based entirely on common myths prevalent in the community and on stereotypes. Similarly, other international studies founded out teachers' attitudes were significantly less positive (Smith, 2000). The authors reasoned that this could probably be due to limited or non-existent training to acquire integration competencies, the limited opportunities for integration in some of these countries, teaching experiences, and experience with students with special education needs. Many regular education teachers who felt unprepared and fearful to work with learners with disabilities in regular classes displayed frustration, anger and negative attitudes toward inclusive education because they believed it could lead to lower academic standards (Gary, 1997). Another study by Vaughn, Schumm, Jallad, Slusher and Saumeel (1996.) examined special education teachers' attitude of inclusion using focused group interviews. The majority of these teachers, who were currently participating in inclusive programs, had strong negative attitudes to inclusion. The teachers identified several factors that would affect the success of inclusion, such as class size, inadequate resources and lack of adequate training.

Researchers reported that teachers had more positive attitudes to inclusion (Ward et al., 1994; York, Vandercock, MacDonald, Heise-Neff, \& Caughey, 1992) and that special education resource teachers tended to have a more positive attitude to inclusion than their mainstream counterpart (Ibid). According to Miller (2001), teachers tended to develop positive attitudes towards students that present with a neat and clean appearance, those who are known to come from educated families, and those who are able to conform to the teacher's own middle-class standards. A teacher can develop his/her own children of choice and term them (Jussim \& Harber, 2005). These children will get a lot of favors from the teacher such as the first to get textbooks and thereby promoting their academic performance.

On the contrary, few researchers reported that teachers had uncertain or neutral attitudes towards including students with disabilities in the general classroom (Bennett, Deluca, \& Bruns, 1997, Leyser \&Tappendorf, 2001)

Researchers do not reach an agreement on the attitude of teachers towards including students with disabilities in to the regular classroom. This controversy disparity showed that it needs further research to determine the attitude of teachers towards the inclusion of students with disabilities in to the regular classroom of South Gondar Administrative towns (which is found in Amhara region-Ethiopia). Thus, the researcher tried to understand the current attitude of teachers towards the inclusion of students with disabilities in to the regular classroom to design better academic and social interventions services for the schooling of students with disabilities in the inclusive classroom, and provide information to practitioners in order to build inclusive school culture and society.

Based on this premises, the researcher formulated the following leading questions:

1. What attitudes do regular schools teachers have to the inclusion of students with disabilities in the regular classroom?

2. Is there a significant difference in the attitude of teachers towards the inclusion of students with disabilities in the regular classroom in relation to their age, gender, teaching experience, and types of training?

3. Which independent variables (age, sex, teaching experience, types of training) are more the predictable dependent variable for the inclusion of students with disabilities in to the regular classroom?

4. Is there a significant difference in teachers' attitude to the selected primary schools?

\section{Research Method}

\subsection{Research Design}

This study assessed the current attitude teachers have towards the inclusion of students with disabilities in to the regular classroom in the selected primary schools of south Gondar administrative town.-Data collection tools included a descriptive survey method was employed, because it is useful-to analyze, interpret and report the status of an existing condition, and to determine the adequacy of status by comparing it with established standards (Koul, 2006).

\subsection{Study Site}

The study was carried out in the selected primary schools found in the administrative towns of south Gondar zone in Amhara Region, Ethiopia. This zone is named for the city of Gondar, which was the capital of Ethiopia until the mid-19th century, and has often been used as a name for the local province. It is bordered on the south by Misrak Gojjam, on the southwest by Mirab Gojjam and Bahir Dar, on the west by Lake Tana, on the north by North Gondar, on the northeast by Wag Hemra, on the east by Semen Wollo, and on the southeast by Debub Wollo; the Abbay River separates South Gondar from the two Gojjam Zones. In this clarify exactly which zone you refer to Zone, there are five administrative townsWoreta, Debre Tabor; Addis Zemen; Mekane Eyesus and Nifas Mewocha upon which this study focused on their primary schools. 


\subsection{Participants of the Study Population, Sample and Sampling Technique}

The participants of this study were teachers in the selected primary schools found in the five administrative towns of the South Gondar zone- Debre Tabor, Nefas Moucha, Addis Zemene, Mekaneyesus and Woreta. Each-school accepts students with disabilities in to the regular classroom, after grade 3 for students with intellectual disabilities \& visual impairment, and after grade 4 for students with hearing impairment. All students had previously attended a primary school in a segregated class room.-A total of 280 regular and practicum teachers that taught students with special needs from grade 5 to 8 participated in the study-through purposive sampling techniques.

\subsection{Variables of the Study}

The independent variables that were employed in this research for statistical comparison includes:

The socio-demographic characteristics such as age, gender, teaching experience and $\mathrm{t}$-service and pre-service-training, and the five selected primary schools settings

The dependent variables include the teacher's attitudes towards inclusion of students with different disabilities in the regular classroom using a standardized questionnaire set through a five- point Likert scale type.

\subsection{Data Gathering Instrument}

In order to survey the attitude of teachers towards the inclusion of students with different disabilities in the regular classroom of South Gondar Administrative towns, a structured questionnaire (Cullen, 2010) were adapted. The test is called the Teacher Attitude Towards Inclusive Scale (TATIS) that is used to evaluate teachers' attitude towards the inclusion of students with disabilities. The reliability of the instrument was assessed and found to be over all correlation coefficient of 0.821 . The contents of the questionnaire included: socio-demographic data which was designed to gather information regarding sex, age, teaching experience and types of training of the respondent teachers. The second part of the questionnaire consist of those items that were directly assessing the attitude of teachers towards the inclusion of students with disabilities in to the regular classroom. The nature of questionnaire was a five- point Likert scale type used to assess the attitude of teachers towards the inclusion of students with disabilities in the regular classroom. A questionnaire was distributed over those teachers that have been teaching from grade 5-8 of the sampled primary schools. The items of the questionnaire were close ended type-and consisted of 17 questions. Some of the items in the closed ended questions were positively word and others were negatively worded in order to counter possible bias. This questionnaire format allowed the researcher to discover the responses, the individuals give spontaneously, and avoid bias that may results from suggesting responses to the individuals. Moreover, the questionnaire was set and translated into Amharic language for easy communication.

\section{Method of Data Analysis Methods}

In this study, quantitative approaches were used to analyze the data obtained through the above instruments. Both descriptive and inferential statistics including t-tests, one Way ANOVA and regression analysis, were used as quantitative methods of analyzing the data obtained through questionnaire. The descriptive statistics using means, frequency count, standard deviations and percentages were used to calculate teachers' attitudes towards the inclusion of students with disabilities towards the regular classroom and their socio-demographic variables.

The $\mathrm{t}$ - test was used to investigate if there is a statistical difference in teachers' attitude across sex and types of training. The One Way ANOVA was used to examine the relationship between teachers' age and years of teaching experience, and their attitudes to inclusion. Multiple regression was used to see which socio demographic variable (sex, age, years of experience and the type of training) more influences teacher's attitude on the inclusion of students. This test also used to predict the independent variables to the attitude of teachers to the inclusion of students with disabilities in to the mainstream classroom. One Way ANOVA is used to analyze the attitude of teachers to inclusion of students with disabilities across the selected primary school. The Po-Hoc test was used to compute the statistical difference between teachers' attitude in relation to the selected sample schools. SPSS version 20 (SPSS Inc., Chicago, IL, USA) software program was used to statistical analyses.

The data from questionnaires were analyzed to obtain descriptive statistics, frequency, percentage, mean and scale for their relationships according to the study objectives, theoretical and conceptual framework using Likert's scales of 5 -points to analysis variables. The rating scales in the questionnaires to attitude were analyzed by valuing (1, 2, 3, 4 and 5) as follows:

Interval=Maximum-Minimum/maximum (5-1/5=0.8)

$$
\text { Interval }=0.8
$$

The-teachers' personal data, the degrees of attitude and contributions to positive development scales varied each by 0.8 points, which could be clarified for all sections as follows: 
$1-1.8=$ very low, strongly disagree and strong negative attitude

1.81-2.6=low, disagree and negative attitude

2.61-3.4=medium, neutral and (Neither negative or positive)

3.41-4.2=high, agree and positive attitude

4.21-5= very high, strongly agree and strong positive

Thus, quantitative analysis was used for the quantifications of major themes and phenomena that consisted of quantifiable variables expressed in numerical figures and magnitudes.

\subsection{Ethical Consideration}

Before gathering data from teachers, principals and supervisors, the researcher sought permissions from the schools and the above informants through a formal letter. The participants were informed to the significance and the purpose of the study and the researcher reassured the participants that their information will remain private and confidential. Informed verbal consent was obtained from study participants to confirm their willingness for participation after having explained the objectives of the study and the participants were notified of their right to refuse or terminate their involvement with the project at any time.

\section{Result}

\subsection{Socio-Demographic Characteristics of the Study Participants}

In total, 261 study teachers participated filling in the questionnaire, with a response rate of $92.72 \%$. The background characteristics of teachers presented in Table 1 below. Regarding sex, $155(59.4 \%)$ and $106(40.6 \%)$ were males and females respectively. In terms of age, 85 (32.6\%) respondents had between 50-60 years, 48(18.4\%) were between 41 and 50 years, 58(22.2\%) were between 31 and 40 years, and 70(26.8\%) were between 20 and 30 years of age. In addition, 97 respondents $(37.2 \%)$ had between 1 - 10 years of teaching experience; 73 respondents (38\%) had between 11 and 20 years' experience; $45(17.2 \%)$ also were between 21 and 30, and the remaining respondents 46(17.6\%) were 31 and above years of teaching experiences. Furthermore, $120(46 \%)$, and $141(54 \%)$ of study participants had taken special needs education course or training during the college training or during working time (in-service) respectively. All the participants were from the five schools which accept students with disabilities in to the mainstream schools after grade five.

Table 1. Socio-demographic characteristics of participants in the selected schools, South Gondar Administrative town $(\mathrm{N}=261)$

\begin{tabular}{|c|c|c|}
\hline Sex & f & $\%$ \\
\hline Male & 155 & 59.4 \\
\hline Female & 106 & 40.6 \\
\hline \multicolumn{3}{|l|}{ Age (in years) } \\
\hline 20-30 & 70 & 26.8 \\
\hline $31-40$ & 58 & 22.2 \\
\hline 41-50 & 48 & 18.4 \\
\hline $50-60$ & 85 & 32.6 \\
\hline \multicolumn{3}{|c|}{ Teaching experience ( in years) } \\
\hline 1-10 & 97 & 37.2 \\
\hline 11-20 & 73 & 28 \\
\hline 21-30 & 45 & 17.2 \\
\hline $31-40$ & 46 & 17.6 \\
\hline \multicolumn{3}{|l|}{ Types of training } \\
\hline Pre service & 120 & 46 \\
\hline In service & 141 & 54 \\
\hline \multicolumn{3}{|l|}{ Schools } \\
\hline Tabor & 56 & 21.5 \\
\hline Woreta & 56 & 21.5 \\
\hline Addis Zemen & 59 & 22.6 \\
\hline Estie & 36 & 13.8 \\
\hline Nefas Mewocha & 54 & 20.7 \\
\hline
\end{tabular}

4.2 Attitude of teachers to the Inclusion of Students With Disabilities

The 261 respondents indicated their response in a five-point Likert scale: Strongly agree; Agree; Undecided; Disagree; and strongly disagree with 5, 4, 3, 2 and 1 marks apportioned to their response respectively. The researcher adapted the 17 attitude scale level questions.-The minimum mean scores were 17 ( $1 * 17$ questions). The decision rule was 
determined at $3 * 17=51$ (neutral) by obtaining the mean score of the scoring values. The maximum mean score is $5 * 17=85$ (strongly positive attitude). Thus, items score less than 51 was rejected, and teachers have negative attitude on the inclusion of students with disabilities to the mainstream class.-Those scores above the decision value (cut point mean) were accepted, and these reflected teachers that held a positive attitude on the inclusion of students in the mainstream classroom. Hence, the mean statistics were used to answer the research question. That is, the general actual mean score of this scale and the cut point mean decision valued scores derived from the five-scale questionnaire was 60.86 and 51 respectively. The scale yield a total score, the value of which could range from 17 to 85 . This means the higher the score a respondent achieves, the more positive attitude he/she has for inclusion. Therefore, the actual mean score (60.86) of teachers' attitude scale is fairly greater than the cut point mean score (51). Due to this finding, teachers had fairly positive attitude to the inclusion of students with disabilities in to the mainstream classroom from grade 5 to 8 .

More specifically, the attitude of teachers to the inclusion of students with disabilities in their mainstream classroom was measured by each of the 17 questions. Each question, teachers in all schools did not have a negative attitude to the inclusion of these students in all grade levels. For instance, the responses to 11 of the 17 questions reported that teachers held a positive attitude/perception to the inclusion of students with disabilities in their mainstream classroom. Additionally, questions 5 and 8 reflected that teachers have a strong positive attitude to inclusion. Conversely, teachers were uncertain about the four questions regarding the inclusion of students with disabilities in to the regular classroom.

The questionnaire results detail that the only issue about which teachers felt very strongly positive were to the question: It is seldom necessary to remove students with disabilities from regular classroom in order to meet their educational needs and Most or all regular classrooms can be modified to meet the need of students with disabilities. Teachers,-appeared however, to be unsure of the following questions-I feel inclusion benefits students with disability All students with disabilities should be included in regular education classrooms with "normal" peers to the fullest extent possible Students with disabilities have higher academic achievements when included in the regular education classrooms, and I find that the general education teacher often does not succeed with students with disabilities even when they try their best.

\subsection{Attitude of Teachers to the Inclusion in Relation to Socio-Demographic Variables}

\section{Gender}

A t-test is used to compare the mean overall attitude scores of regular teachers that are male with those who are female. The attitude to teachers in the school was generally positive $(M=60.47, \mathrm{SD}=8.564)$. According to this test, there is statistically significant difference between the attitudes related to gender. That is, male teachers had slightly higher total scores $(\mathrm{M}=61.57, \mathrm{SD}=8.21)$ than their female counterparts. $(\mathrm{M}=58.87, \mathrm{SD}=8.85), \mathrm{t}(-3.527), \mathrm{df}=259, \mathrm{p}$ $=.012<0.05$. Thus, the result of this study indicates that male teachers have slightly positive attitude to the inclusion of students with disabilities in to the regular classroom than their female partners.

\section{Types of training}

A t-test comparing the overall attitude mean scores of regular education teachers' attitude to the inclusion of students with disabilities to the regular class room based on the time of training for special needs education at course level or short training basis indicated there was a statistically significant difference between pre- service and in-service teachers $(\mathrm{t}=4.036, \mathrm{df}=259, \mathrm{p}=000<0.05)$. Hence, the result of this investigation indicated that pre- service teachers are more positively disposed to the inclusion of these students in to the mainstream class ( $M=62.73, \mathrm{SD}=7.367)$ than female teachers $(\mathrm{M}=58.55, \mathrm{SD}=8.612)$. Therefore, pre- service teachers (who took special needs education during college stay) have more positive attitude than in-service teachers (who took special needs education after graduation/ on the job) on the inclusion of students with disabilities in to the mainstream classroom.

\section{Years of Teaching Experience}

An analysis of variance (ANOVA)comparing the mean overall attitude score of regular education teachers to the number of teaching experience they had was conducted. There is a statistically significant difference between the different years of teaching experiences that teachers had $(\mathrm{F}(3,257)=13.96, \mathrm{p}=.000)$. The result of this investigation indicates that teachers with less years of teaching experience are more positively disposed to including students with disabilities in to the regular classroom as compared with higher experienced teachers. The difference between their responses is significant $(p<0.001)$. In this case, the mean score of less experienced teachers represent slightly greater (59.00, $\mathrm{SD}=9.025)$ than the higher experienced teachers $(\mathrm{M}=54.526 . \mathrm{SD}=7.571)$.

\section{Age}

An analysis of variance (ANOVA) was comparing the mean scores of regular education teachers' attitude to the inclusion of students with disabilities in to the regular classroom based on their age levels indicated that there was a statistically significant difference between their age levels that teachers had $(\mathrm{F}(3,257)=11.364, \mathrm{p}=.000)$. The result of this study indicates that teachers with lower age levels/ younger had more positively disposed to including students with 
disabilities in to the regular classroom as compared with those teachers which are found at the higher age levels/older. The difference between their responses is significant $(\mathrm{p}<0.001)$. In this case, the mean score of younger teachers $(M=$ 65.143, $\mathrm{SD}=7.161$ ) represent a slightly positive attitude to the inclusion of students with disabilities in to the mainstream class in compression with older teachers $(\mathrm{M}=58.435, \mathrm{SD}=.8 .900)$.

\section{The predictor variables}

Regression model provides the $R, R^{2}$, adjusted $R^{2}$, and the standard error of the estimate, which can be used to determine how well a regression model fits the data. It found out that the adjusted $\mathrm{R}^{2}$ of the model is .345 with the $\mathrm{R}^{2}=.119$. This means that the linear regression explains $11.9 \%$ of the variance in the data. The Durbin-Watson $\mathrm{d}=2.074$, which is between the two critical values of $1.5<\mathrm{d}<2.5$. Hence, this can assume that there is no first order linear auto-correlation in the multiple linear regression data. If we would have forced all variables into the multiple regression model, we would have seen a slightly lower $\mathrm{R}^{2}$ and adjusted $\mathrm{R}^{2}$ (.345 and .119 respectively). A value of 0.345 , in this analysis indicates a lower level of prediction. The $\mathrm{R}^{2}$ which is the proportion of variance in the dependent variable (attitude score) that can be explained by the independent variables (age, sex, experience and type of training). Technically, it is the proportion of variation accounted for by the regression model above and beyond the mean model. You can see from the value of 0.345 that the independent variables only explain $11.9 \%$ of the variability of the dependent variable

The linear regression's F-test has the null hypothesis that the model explains zero variance in the dependent variable (in other words $\mathrm{R}^{2}=0$ ). The F-test is highly significant, thus we can assume that the model explains a significant amount of the variance in attitude scale. The $F$-ratio in the ANOVA table tests whether the overall regression model is a good fit for the data. The independent variables statistically significantly predict the dependent variable, $F(4,256)=8.670, p<0.05$ (i.e., the regression model is fit of the data).

The next data also focuses on the four predictors, if they are statistically significant and, if so, which variable(s) is/are highly predictive. The column "Sig." holds the significance levels for our predictors. As a rule of thumb, we say that a b coefficient is statistically significant if its $p$-value is smaller than 0.05 . For instance, the average age $(b=-1.796)$ is significant $(\mathrm{p}=0.000)$. Next, the effect of $\operatorname{sex}(\mathrm{b}=-2.556, \mathrm{p}=.014)$ is significant. The average teaching experience $\mathrm{b}=-0.032$ are not significant $(\mathrm{p}=.966)$ and it is not a predictive variable. .Finally, the types of training teachers took, $b=-1.415$, $\mathrm{p}=.2321$ ) seems to be unrelated to attitude. Thus, it is concluded that two of four b coefficients are statistically significant. For instance, teachers' sex and age levels are predictor factors of predicting attitude. Of these, teachers' sex is the highest predictive variable that predicts the dependent variable than others. On the contrary, it would seem to indicate that teachers teaching experience and type of training are not an important factor of predicting the dependent variable attitude. (The mean difference is significant at the 0.05 level) A multiple regression was run to predict dependent variable from gender, age, teaching experience and types of training teachers trained. Thus, the variables statistically significantly predicted the outcome, $F(4,256)=8.670, p<.0005, R^{2}=.345$. Two out of four variables added statistically significantly to the prediction, $p<05$.

\subsection{Difference in Teachers' Attitude as a Function of the Five Schools}

In order to answer the sub-question "Is there a significant difference in teachers' attitude to the selected primary schools?" a One-way between Groups ANOVA were carried out to compute difference in attitude of regular teacher between the five schools.

The One-way Between Groups ANOVA analysis for the attitude of teachers found in different schools as a variable divided into Tabor, Woreta, Addis Zemen, Estie and Nefas Mewucha showed statistical significant differences at the $\mathrm{p}<.05$ level on attitude scores among the five groups $[\mathrm{F}(4,257)=8.53 \mathrm{p}=.000]$. The Tukey HSD post hoc tests showed there is significant difference between Woreta and Tabor (Mean $=55.821$ and 63.71 respectively); Woreta and Nefas Mewucha (Mean = 55.558 and 61.074 respectively); Woreta and Estie (Mean=55.558 and 63.5833 respectively). However, there is no spastically significant difference between the mean score of Woreta and Addis Zemen (Mean=55.822 and 59.356

\section{Discussion, Conclusion and Recommendation}

\subsection{Discussion}

Descriptive statistics were used to analysis the attitude of teachers to the inclusion of students with disabilities in to the regular/mainstream class. The result showed that the general actual mean score (60.86) of teachers' attitude scales is fairly greater than the cut points mean score (51). Due to this reason, teachers had fairly positive attitude to the inclusion of students with disabilities in to the mainstream classroom from grade 5 to 8 . More specific, the attitude of teachers to the inclusion of students with disabilities in to the mainstream class room per item were analyzed. In each item of the questionnaire, teachers in all schools did not have a negative attitude to the inclusion in all grade levels. However, Patricia (1997) found out that the attitude of primary school teachers towards inclusive education 
demonstrated mostly negative towards inclusion. In addition. Smitha and Acharya (2010) also found out that the attitude of teachers towards the inclusion of students with disabilities have unfavorable.

Attitudes play a significant role in determining behavior (Azjen \& Fishbein, 1980. It is therefore important to ascertain the factors shaping the attitudes of mainstream teachers as they attempt to include students with disabilities. The factors are gender, teachers teaching experience, age levels, types of training etc. In this research, the researcher tried to investigate the attitude of teachers in relation to these factors. Therefore, the finding shows that there is statistically significant difference between teachers' attitudes in relation to gender. That is male teachers had slightly higher total scores $(\mathrm{M}=61.57, \mathrm{SD}=8.21)$ than their female contemporaries $(\mathrm{M}=58.87, \mathrm{SD}=8.85), \mathrm{t}(-3.527), \mathrm{df}=259, \mathrm{P}$ $=.012<0.05$. Thus, male teachers have slightly positive attitude than female teachers. However, several studies have reported that female teachers have more positive attitudes towards individuals with disabilities (Nabors and Larson, 2002; Nabuzoka and Ronning, 1997). In addition, based on the time of training for special needs education at course level or short term training indicated that there was a statistically significant difference between pre- service and in-service teachers training $(\mathrm{t}=4.036, \mathrm{df}=259, \mathrm{P}=000<0.05)$., The result of this investigation indicated that pre- service teachers training have positive attitude to the inclusion of these students to the mainstream class $(\mathrm{M}=62.73, \mathrm{SD}=7.367)$ than female teachers. In relation to this finding, study conducted by Leyser and Tappendorf (2001), Van Reusen, Soho, and Barker (2001), Bender, Vail, and Scott (1995) showed the same results that general education teachers in pre-service training and on working with students with special needs had more positive attitude towards inclusion. On the contrary, Hastings and Oakford (2003) and Van Reusen et al., (2001) reported that pre-service teachers expressed more negative attitude towards the inclusion of students with disabilities in to the mainstream class.

In relation to attitude of teachers by their teaching experience, there is a statistically significant difference between the different years of teaching experiences that teachers had $(\mathrm{F}(3,257)=13.96, \mathrm{P}=.000)$. The result of this investigation indicates that teachers with less years of teaching experience have positive attitude to inclusion as compared to higher experienced teachers. This result is in line with the previous studies, such as Hastings and Oakford's (2003), Cornoldi et al., 1998). Hsien, Brown and Bortoli (2009) which revealed teachers with more years of experience had more negative attitudes. In relation to the age levels of teacher analysis of variance showed that there was a statistically significant difference between their age levels that teachers had $(\mathrm{F}(3,257)=11.364, \mathrm{P}=.000)$. The result of this study indicates that younger teachers had more positive attitude to the inclusion of students with disabilities in to the regular classroom as compared with those older teachers which is in line with other studies conducted earlier (Forlin, Douglas and Hattie, 1996).The reason is that younger teachers have taken special needs education course during the college stay than the older teachers.

Identifying variables that predict attitudes of teachers toward students with disability is essential to develop interventions (Rao et al., 2004). Researchers have conducted studies of other nations that highlight specific factors and their association with predicting attitudes. (Rao et al., 2010), Antonak and Livneh (2000) also maintained that scholars and researchers must first critically assess the attitude of professionals before attempting to modify the general population's perceptions of the disability community. For this purpose, the researcher tried to intestate the predictive variables. Thus, the result showed that the $\mathrm{R}^{2}$ which is the proportion of variance in the dependent variable that can be explained by the independent variables (age, sex, experience and type of training found out that the adjusted $\mathrm{R}^{2}$ of the model is .345 with the $\mathrm{R}^{2}=.119$. This means that the linear regression explains $11.9 \%$ of the variance in the data. The $F$-ratio in the ANOVA tests, the overall regression model is a good fit for the data. The independent variables were statistically significantly to predict the dependent variable, $F(4,256)=8.670, P<0.05$. Hence, the regression model is fit of the data. A multiple regression was run to predict dependent variable from gender, age, teaching experience and types of training teachers have trained. Thus, the variables statistically significantly predicted the outcome, $F(4,256)=8.670$, $P<.0005, R^{2}=.345$. Sex and age variables added statistically significantly to the prediction, $p<05$. However, other research findings found out that age alone has not always been a predictor of attitudes but was thought instead to coincide with years of teaching experience (Alghazo et al., 2004; Mazurek \& Winzer, 2011).

Inclusion practices differ, however, from one country to the next (Bines \& Lei, 2011), and even within school districts and between classrooms. Unless teachers change their pedagogy to meet students' needs, the physical placement of a student in the classroom may not meet the definition of true inclusion (Freire \& César, 2003; Sailor \& McCart, 2014). According to Singal (2008), teachers need positive beliefs and attitudes about inclusion as much as they need to know how to implement inclusion strategies. In relation to this, the researcher tried to investigate the attitude of teachers as a function of place/school. The One-way Between Groups ANOVA analysis for the attitude of teachers showed statistical significant differences at the p<.05 level on attitude scores among the five groups $[\mathrm{F}(4,257)=8.53 \mathrm{p}=.000]$ According to Neary \& Halvorsen (1995), "the best environment for learning are those in which students are motivated, learning is active and information is presented in a manner that recognizes the diversity of each student". The Tukey HSD post hoc tests of this study also showed that there is significant difference between Woreta and Tabor (Mean $=55.821$ and 63.71 respectively); Woreta and Nefas Mewucha (Mean $=55.558$ and 61.074 respectively); Woreta and Estie (Mean=55.558 and 63.5833 respectively). 


\section{Conclusion}

Based on the results of the study, the following conclusions were drawn

1. The general mean score of teachers' attitude scale is fairly greater than the cut point mean score. Due to this fact, teachers had slightly positive attitude to the inclusion of students with disabilities in to the mainstream classroom. More specific, the attitude to teachers to the inclusion of students with disabilities in to the mainstream class room per item also showed that teachers did not have a negative attitude to the inclusion of these students in to the mainstream classroom.

2. There is statistically significant difference between teachers' attitudes in relation to gender, types of training, teaching experience, and age levels. The result showed that male teachers had slightly higher total scores than their female counterparts. Thus, male teachers have slightly positive attitude than female teachers towards the inclusion. Besides, pre- service teachers have positive attitude to the inclusion of these students in to the mainstream class. In addition, teachers with less years of teaching experience have positive attitude to inclusion as compared to higher experienced teachers. Furthermore, younger teachers have a positive attitude to the inclusion of students with disabilities in to the mainstream class than older teachers.

3. The results of multiple regression also showed that the dependent variable that can be explained by the independent variables found out the adjusted $\mathrm{R}^{2}$ of the model is .345 with the $\mathrm{R}^{2}=.119$. Thus, the linear regression only explains $11.9 \%$ of the variance in the data. This shows that there are other independent variables which explains the dependent variable that are not included in this study. In addition, the independent variables were statistically significant to predict the dependent variable, $\mathrm{F}(4,256)=8.670, \mathrm{P}<0.05$. Particularly, the study found out that gender and age variables was statistically significantly to predict the dependent variable.

4. The One-way Between Groups ANOVA analysis for the attitude to teachers as a function of schools showed a statistical significant differences between the five schools. The Tukey HSD post hoc tests also showed that there is a statically significant difference between Woreta and other three schools.

\section{Recommendation}

This study can contribute to the knowledge in preparing teachers to address the diverse needs of students with disabilities, and plan the inclusion program in the Ethiopian educational system. Therefore, the researcher forward the following recommendations to the concerned bodies based on the research findings.

1. The Ministry of Education (MOE) should include a number of special needs and /inclusive education courses to the college and university training programs so that all graduate teachers will get the opportunity to scale up their knowledge and skills about special needs education., This in turn will help teachers develop positive attitudes towards students with disabilities, assisting students with disabilities in the regular educational program. In addition, schools should collaborate with universities and the regional educational bureau to provide on-the-job training in order to scale up the knowledge and skills of experienced teachers.

2. The academic ability and achievement of students with disabilities in the mainstream classrooms are highly dependent on the attitude of regular classroom teachers have to the inclusion program in their classroom. The positive attitude of teachers towards inclusion is highly depending on the knowledge or skills they have; the type of training they have; and the sex and age levels of teachers.-Teachers should improve their knowledge and skills about special needs education on a continuous basis.

3. The effectiveness of inclusion is highly dependent on the positive attitude schools have towards mainstream and students with disabilities. Hence, schools should work more on how to respect, appreciate, value and respond to diversity by giving on-going professional development training for all teachers at schools. This in turn helps staff members to have a good attitude to the program and to students with disabilities.

4. This study concluded that most teachers were aware about the inclusion of students with disabilities in the regular classroom. However, some regular school teachers did not have sufficient information about the program, leading some teachers to build negative attitudes towards students with disabilities. As a result, more needs to be done to spread an awareness regarding inclusion of students with disabilities in the regular classroom. Schools should design awareness creation programs in collaboration with special needs education professionals to maximize their awareness.

5. Experienced teachers should work collaboratively and cooperatively with the young teachers sharing ideas and information about special needs/inclusive education, and arrange ongoing support for students with disabilities.

6. To include a special needs education course in the curriculum of teachers training program at college or university, and providing training in the pre-service and in-service program for new graduates and experienced teachers respectively in order to scale up their knowledge and skills about special needs education, it requires a large amount 
budget and resources Clumsy sentence - consider re-writing. Hence, the government should allocate sufficient budget to run the program and training.

7. Particularly, sign language and braille skills training should be provided for regular education teachers to maximize their communication capabilities with students with sensory impairment, and in turn to assist these students in any aspects of their education.

8. The socio demographic variables only explained $11.9 \%$ of the dependent variable. Thus, the researcher invite other interested researchers to investigate the other independent variables that directly explain and fit the dependent variable (attitude).

\section{References}

Ajzen, I., \& Fishbein, M. (1980). Understanding Attitudes and Predicting Social Behavior. Englewood Cliffs, NJ: Prentice Hall.

Alghazo, E. M., Gaad, N., \& El, E. (2004). General education teachers in the United Arab Emirates and their acceptance of the inclusion of students with disabilities. British Journal of Special Education, 31(2), 94-99. https://doi.org/10.1111/j.0952-3383.2004.00335.x

Antonak, R. F., \& Livneh, H. (2000). Measurement of attitudes towards persons with disabilities. Disability and Rehabilitation, 22, 211-224. https://doi.org/10.1080/096382800296782

Bender, W., Vail, C., \& Scott, K. (1995). Teachers' attitudes toward increased mainstreaming: Implementing effective instruction for students with learning disabilities. Journal of Learning Disabilities, 28(2), 87-94. https://doi.org/10.1177/002221949502800203

Bennett, T., Deluca, D., \& Bruns, D. (1997). Putting inclusion into practice: Perspectives of teachers and parents. Exceptional Children, 64, 115-131. https://doi.org/10.1177/001440299706400108

Boer, A., Pijl, S., Minnaert, A. (2009). Attitudes of parents towards inclusive education: a review of the literature. European Journal of Special Needs Education, 25(2). https://doi.org/10.1080/08856251003658694

Cornoldi, C., Terreni, A., Scruggs, T. E., \& Mastropieri, M. A. (1998). Teacher attitudes in Italy after twenty years of inclusion. Remedial and Special Education, 19(6), 350-356. https://doi.org/10.1177/074193259801900605

Creswell, J. W. (2002). Educational research: planning, conducting, and evaluating quantitative and qualitative research. Upper Saddle River, NJ: Pearson Education.

Deisinger, J. A. (2000). Promoting acceptance of persons with disabilities in inclusive communities. In F. E. Obiakor, S. A. Burkhart, A. F. Rotatori \& T. Wahlberg (Eds.), Intervention techniques for individuals with exceptionalities in inclusive settings (pp. 299-326). Stamford: JAI Press.

Florian, L. (2008). Special or Inclusive Education: Future Trends. British Journal of Special Education, 35(4), 202-208. https://doi.org/10.1111/j.1467-8578.2008.00402.x

Forlin, C., Douglas, G., \& Hattie, J. (1996). Inclusive practices: how accepting are teachers? International Journal of Disability, Development and Education. https://doi.org/10.1080/0156655960430203

Freire, S., \& César, M. (2003). Inclusive ideals/inclusive practices: How far is a dream from reality? Five comparative case studies. European Journal of Special Needs Education, 18(3), 341-354. https://doi.org/10.1080/0885625032000120224

Gaad, E., \& Khan, L. (2007). Primary mainstream teachers' attitudes towards inclusion of students with special educational needs in the private sector: A perspective from Dubai. International Journal of Special Education, 22(2), 95-108.

Gilmore, L., Campbell, J., \& Cuskelly, M. (2003). Developmental expectations, personality stereotypes, and attitudes towards inclusive education: community and teachers views of Down syndrome. International Journal of Disability, Development and Education, 50(1), 65-76. https://doi.org/10.1080/1034912032000053340

Hasting, R., \& Oakford, S. (2003). Student teachers' attitudes towards the inclusion of children with special needs. Educational Psychology, 23(1), 87-94. https://doi.org/10.1080/01443410303223

Hsien, M., Brown, M., \& Bortoli, A. (2009) 'Teacher qualifications and attitudes toward inclusion.' Australasian Journal of Special Education, 33(1), 26-41. https://doi.org/10.1375/ajse.33.1.26

Jussim, L., \& Harber, K. D. (2005). Teacher expectations and self-fulfilling prophecies: Known and unknowns, resolved and unresolved controversies. Personality and social Psychology. https://doi.org/10.1207/s15327957pspr0902_3 
Koul, L. (2006). Methodology of Educational Research. (6th Ed.). New Delhi, Bikas publishing House pvt.ltd.

Leyser, Y., \& Tappendorf, K. (2001). Are attitudes and practices regarding mainstreaming changing? A case of teachers in two rural school districts. Education, 121, 751-760.

Mazurek, K., \& Winzer, M. (2011). Teacher attitudes toward inclusive schooling: Themes from the international literature. Education and Society, 29(1), 5-25. https://doi.org/10.7459/es/29.1.02

McFarlane, K., \& Wolfson, L. M. (2013). Teacher attitudes and behavior toward the inclusion of children with social, emotional and behavioral difficulties in mainstream schools: an application of the theory of planned behavior. Teaching and Teacher Education, 29, 46-52. https://doi.org/10.1016/j.tate.2012.08.006

Miller, R. (2001). Greater expectations to improve students learning. Paper submitted to association of American colleges and universities, Retrieved from http://www.greaterexpectations.org/ Accessed on 16/04/13

Nabors, L., \& Larson, E. R. (2002). The effects of brief interventions on children's playmate preferences for a child sitting in a wheelchair.' Journal of Developmental and Physical Disabilities, 14, 403-413. https://doi.org/10.1023/A:1020339004125

Neary, T., \& Halvorsen, A. (1995). What is Inclusion? ERIC Digest, ED.393248.

Norwich, B. S. (1994). The relationship between attitudes to the integration of children with special educational needs and wider socio-political views: a US-English comparison. European Journal of Special Needs Education, 9, 91-106. https://doi.org/10.1080/0885625940090108

Patricia, B. (1997). The attitudes of primary school teachers towards inclusive education. Retrieved from https://ujdigispace.uj.ac.za/handle/10210/5824

Rao, D., Horton, R., Tsang, H., Shi, K., \& Corrigan, P. (2010). Does individualism help explain differences in employers stigmatizing attitudes toward disability across Chinese and American cultures? Rehabil. Psychol., 55(4), 351-359. https://doi.org/10.1037/a0021841

Ross-Hill, R. (2009). Teacher attitude towards inclusion practices and special needs students. Journal of Research in Special Needs Education, 9(3), 188-198. https://doi.org/10.1111/j.1471-3802.2009.01135.x

Sailor, W. S., \& McCart, A. B. (2014). Stars in alignment. Research \& Practice for Persons with Severe Disabilities, 39(1), 55-64. https://doi.org/10.1177/1540796914534622

Singal, N. (2008). Working towards inclusion: Reflections from the classroom. Teaching and Teacher Education, 24(6), 1516-1529. https://doi.org/10.1016/j.tate.2008.01.008

Smith, M. G. (2000). Secondary teachers' perceptions toward inclusion of students with severe disabilities. NASSP Bulletin, 84(613), 54-60. https://doi.org/10.1177/019263650008461309

Tait, K., \& Purdie, N. (2000). Attitudes toward disability: Teacher education for inclusive environments in an Australian university. International Journal of Disability, Development and Education, 47(1) 25-38. https://doi.org/10.1080/103491200116110

United Nation (1989) Convention on the Rights of the Child (New York, UN.).

Van Reusen, A., Soho, A., \& Barker, K. (2001). High school teacher attitudes toward inclusion. High School Journal, 84(2), 7-21.

Villa, R. A., \& Thousand, M. N. (1996). Teacher and administrator perceptions of heterogeneous education. Exceptional Children, 63(1), 29. https://doi.org/10.1177/001440299606300103

Ward, J., Centre, Y. \& Bochner, S. (1994). A question of attitudes: integrating children with disabilities into regular $\begin{array}{lllll}\text { classrooms. British Journal of Special } & \text { Education, } & 21(1), & 34-39 .\end{array}$ https://doi.org/10.1111/j.1467-8578.1994.tb00081.x

York, J., Vandercook, T., MacDonald, C., Heise-Neff, C., \& Caughey, E. (1992). Feedback about integrating middle-school students with severe disabilities general education. https://doi.org/10.1177/001440299105800307

\section{Copyrights}

Copyright for this article is retained by the author(s), with first publication rights granted to the journal.

This is an open-access article distributed under the terms and conditions of the Creative Commons Attribution license which permits unrestricted use, distribution, and reproduction in any medium, provided the original work is properly cited. 